EstAg 32 (1997) 407-430

\title{
Estructura de la Regla de san Agustín (I)
}

Según el gran estudioso y conocedor de la Regla monástica del obispo de Hipona, el P. Lucas Verheijen, OSA, ésta debió ser compuesta en torno al año 397; opinión que, apoyados en su autoridad y argumentos, comparten unos autores, pero rebaten otros ${ }^{1}$. Si tal fecha responde a la verdad histórica, nos hallamos en su décimo sexto centenario. Buena oportunidad para acercarnos al célebre documento en un nuevo esfuerzo por comprenderlo mejor.

1. Cf. L. VerheIJEN, La Loi et la grâce. La «date ancienne» et la «date récente» du Praeceptum (Non sicut serui sub lege sed sicut liberi sub gratia constituti), en Scientia Augustiniana (Festschrift A. Zumkeller), Würzburg, 1975, pp. 76-91; NA I, 58-73; Spiritualité et vie monastique chez saint Augustin. L'utilisation monastique des Actes des Apôtres 4, (31)3235, en Jean Chrisostome et Augustin (Actes du Colloque de Chantilly 22-24 septembre 1974). París 1975, pp. 93-123; en concreto, p. 102-106.

La cuestión fue muy discutida en otros tiempos, hoy día ya no tanto. Antes de los estudios de L. Verheijen las fechas propuestas habían sido fundamentalmente tres. Según algunos, san Agustín habría compuesto la Regla poco después de su ordenación sacerdotal (a. 391), para la comunidad del Monasterio del huerto (cf. W. HÜMPFNER, Die Mönchsregel des heiligen Augustinus, en Augustinus Magister, I 241-254; P. MANDonnet, Saint Dominique, Paris 1937, II,135ss). Según otros, apoyándose en diferentes argumentos, la Regla habría visto la luz en los años inmediatamente siguientes a su ordenación episcopal (cf. A. ZUMKELLER, Das Mönchtum des heiligen Augustinus, Würzburg $1968^{2}$, p. 329; T. VAN BAVEL, Parallèles, vocabulaire et citations bibliques de la "Regula sancti Augustini": Contribution au problème de son authenticité, en Augustiniana 9 (1959) 12-77; D. SANCHIS, Pauvreté monastique et charité fraternelle chez saint Augustin: Le commentaire augustinien de Actes 4,32-35 entre 393 y 493, en Studia Monastica 4 (1962) 7-33. L. Cilleruelo, por su parte, la retrasa un poco más, vinculándola al De opere monachorum (cf. Nota sobre la fecha de composición de la Regula Augustini, en Archivo Agustiniano 55 [1961] 257-261, [hacia el 401-402]). Otros, por último, optaron por una fecha muy tardía, el 428 (cf. A. SAGE, La Regla de san Agustín comentada en sus obras, Madrid 1986, pp. 147-149 (original francés: La Règle de saint Augustin commenté par ses écrits, Paris 1961); A. C. VEGA, Notas histórico-críticas en torno a los orígenes de la Regla de san Agustín, en Boletín de la Real Academia de la Historia 152 (1963) 13-94; A. MANRIQue, La vida monástica en san Agustín, El Escorial-Salamanca 1959, 454-464.

Después de los estudios del docto agustino, buena parte de los autores se han alineado con su tesis. Pero no todos. L. Cilleruelo se mantuvo en sus posiciones (cf. Conclusiones sobre la Regula Augustini, en Revista Agustiniana de Espiritualidad 10 (1969) 49-86, en concreto, p. 86 [hacia el 403]). La tesis defendida por Vega, Sage y Manrique ha encontrado otro defensor 


\section{INTRODUCCIÓN}

Las catedrales románicas reflejan la espiritualidad de los siglos XI-XIII, las góticas la de los siglos XIV-XV. La arquitectura religiosa, como la civil, responde a las concepciones del arquitecto o del grupo humano al que este sirve. Dicho arte es, por ello, uno de tantos cauces de que dispone el historiador para conocer la mentalidad de una época. La penumbra y silencio recogido de los recintos románicos, igual que las enhiestas agujas del gótico, dan tanta información sobre la espiritualidad de la época en que vieron la luz como muchos documentos escritos, que surgieron precisamente para ofrecer esa información.

También los textos escritos tienen su propia arquitectura. Así cabe designar la estructura o modo de disponer las diversas partes que lo componen. Pero mientras la estructura de los edificios es perceptible de ordinario a los ojos, la arquitectura de las obras literarias ${ }^{2}$, con frecuencia, sólo resulta perceptible a la mente y, a veces, después de no poco esfuerzo. Como la de los edificios, también la de las obras literarias se constituye en valiosa fuente informativa para el historiador de la cultura.

La Facultad de Arquitectura literaria en la antigüedad era la escuela de Retórica. En ella aprendía el alumno el arte de la composición, el modo de «construir» libros. Es de suponer, pues, que la condición de afamado rhetor de Agustín haya quedado reflejada también en su arte de componer. La suposición es tan lógica que algunos críticos lo han constituido en criterio para juzgar la autenticidad de sus escritos ${ }^{3}$. El problema radica en que nuestros gustos y criterios no siempre coinciden con los de su época. Así se explica que el

en L. Rubio (cf. La norma fundamental de la vida monástica según san Agustín y otras reflexiones en torno a la Regula Augustini, en La ciudad de Dios 183 (1970) 189-235; en concreto, p. 234; El ideal monástico de san Agustín y otras cuestiones anejas, en La ciudad de Dios 196 (1983) 5-56; en concreto, p. 39. 54-55). B. Rano, por su parte, considera que «el año 397 es una hipótesis -valga la redundancia- totalmente hipotética» y juzga que fue escrita varios años después de dicha fecha, «tal vez no antes del 415» (cf. La obra "El espejo", clave para la comprensión de la "Regla de san Agustín”, en Estudio Agustiniano 32 81967) 5-25; en concreto, p. 21).

Nosotros aceptamos, de momento como simple hipótesis de trabajo, que la fecha de composición de la Regla coincide con la propuesta por L. Verheijen, es decir, en torno al 397 . Al final del estudio fijaremos nuestra posición.

2. Entendemos por obra literaria cualquier escrito.

3. Así R. Lorenz, entre otras razones para negar la paternidad agustiniana de la Regula ad seruos Dei, aduce el hecho de su deficiente composición (cf. Die Anfänge des abendländischen Mönchtum im 4. Jahrhundert, en Zeitschrift für Kirchengeschichte 77 (1966) 1-61; en concreto, p. 60-61. 
gran patrólogo H.I. Marrou osase afirmar que san Agustín componía mal ${ }^{4}$. Juicio precipitado de joven presuntuoso, como él mismo reconocería después en sus propias «Retractaciones», escritas a imitación de las agustinianas 5 .

$\mathrm{Al}$ acercarse a cualquier escrito del obispo de Hipona, es, pues, deseable hacer el esfuerzo necesario para descubrir la estructura interior del mismo. Sin duda será rentable. No sólo para poder juzgar desde criterios estéticos si el Santo componía bien o mal, sino también, sobre todo, según lo dicho anteriormente, para entender el texto, para descubrir la mente de su autor en el momento de escribirlo. Sabido es que algunos se olvidaron de la prudente sobriedad y se deslizaron hacia el pseudoarte de lo rebuscado; es lo que aconteció en la corriente cultural denominada asianismo. Pero no cabe pensar que fuera ese el caso del obispo Agustín, obsesionado por el deseo de ser entendido por sus fieles ${ }^{6}$, hasta el punto de aceptar incorrecciones gramaticales, con tal de conseguir ese objetivo?.

En el presente trabajo vamos tras la arquitectura interior o estructura de un texto pequeño, la «Regla a los siervos de Dios» o Praeceptum ${ }^{8}$. Se trata de un documento sobre el que se ha escrito abundantemente, sobre todo en los últimos cincuenta años, y que ha sido objeto de numerosos estudios o comentarios ${ }^{9}$. Como se verá luego, las hipótesis sobre la estructura subyacente se

4. Saint Augustin et la fin de la culture antique, Paris 1938, p. 61.

5. Retractations, Paris 1949, p. 665 : «jugement d'un jeune barbare et ignorant et présomptueux... Reprocher au rhéteur Augustin "de ne pas savoir composer" c'est pretendre que Braque ou Picasso n'étaient pas capables de dessiner une guitare selon les lois de la perspective».

6. Cf. De doctr. christ. 4,12,27-28: CC 32,135-136.

7. Cf. Sermo 37,14; 46,28: CC 41,459.554; De doctr. christ. 2,13,20: CC 32,45-46..

8. El título vulgar «Regla de san Agustín» o el latino Regula ad seruos Dei no es original, como resulta de la edición crítica del P. L. Verheijen (cf. nota siguiente). En el justificado intento de uniformar las diferentes nomenclaturas, L. Verheijen ha otorgado a todos los documentos relacionados con ella un nombre nuevo. Respecto de la «Regla», su propuesta es denominarla Praeceptum, en referencia al praecipimus que aparece en el exordio (I,1). En estas páginas, nosotros seguiremos empleando el término «Regla», por estar ya consagrado y ser el habitualmente en uso en la tradición y específicamente en la Orden de san Agustín.

9. Entre los estudios, merecen reseña especial los de L. Verheijen. Ante todo, La Règle de saint Augustin. I. Tradition manuscrite; II. Recherches historiques, Paris, 1967. Luego los numerosos artículos publicados en distintas revistas y recogidos, buena parte de ellos, en dos nuevas publicaciones: Nouvelle Approche de la Règle de saint Augustin. T. I, Abbaye de Bellefontaine, 1980 (en adelante NA I). T. II: Chemin vers la vie heureuse, Louvain, 1988 (en adelante, NA II). De los restantes, destacamos los más importantes: T. VAN BAVEL, Parallèles, vocabulaire et citations bibliques de la "Regula sancti Augustini"; A. MANRIQUE, La vida monástica en S. Agustín. Enchiridion histórico-doctrinal y Regla. El Escorial-Salamanca 1959; Teología agustiniana de la vida religiosa, Real Monasterio de El Escorial 1964; G. LAWLESS, 
suceden unas a otras, sin que se haya logrado un acuerdo entre los investigadores ${ }^{10}$. Abrigamos la esperanza de que se cumplirá en nosotros lo señalado antes en general: que el esfuerzo realizado será rentable.

La presente investigación constará de cinco partes de desigual extensión. Primero anticipamos la estructura que suponemos subyace a la Regla; luego presentamos las premisas para, a continuación, detenernos en lo que fundamenta nuestro planteamiento, esto es, la existencia de esa misma estructura de composición en varios textos del santo sustancialmente contemporáneos de la Regla, de acuerdo con la hipótesis de trabajo: De vera religione ${ }^{11}$, el libro décimo de las Confessiones ${ }^{12}$, los nueve primeros libros de las mismas Confessiones, los Sermones sobre la Cuaresma y la Epistula 48. Cada uno de esos textos será comparado con el monástico. Seguirá un acercamiento a algunas cuestiones concretas que plantea nuestro documento y, como conclusión, ofreceremos una visión de él en su conjunto.

Augustine of Hippo and his Monastic Rule, Oxford 1987; A. DE VOGÜÉ, Histoire littéraire du mouvement monastique dans l'antiquité, III, Paris 1996, pp. 172-204. Para una Bibliografía más amplia, cf. L. VERHEIJEN, La Règle de saint Augustin, II, 221-239, y NA II, 394-400.

Para los comentarios, limitándonos a los modernos, cf. L. Cilleruelo, El monacato de san Agustín y su Regla, Valladolid 1947; Comentario a la Regla de san Agustín, Valladolid 1994; A. Sage, La Regla de san Agustin; A. Zumkeller, The Rule of Saint Augustin with a Commentary. Translated by J. C. Resch, St. Norbert Abbey, De Pere, Wisconsin 1961); A. Trapè, Sant'Agostino: La Regola, Roma 19862; T. VAN BAVEL, Agustín de Hipona: Regla para la comunidad. Comentario de T. v. B. (Traducción al castellano de J. van Zuijlekom y H. van den Berg, Iquitos [Perú] 1986); C. BofF, $A$ via da comunhao de bens, Rio Janeiro 1991 (Traducción castellana de J.G. Ramírez: El camino de la comunión de bienes, Bogotá 1991); Soevr Marie-Ancilla, La Règle de saint Augustin. Préface par Mgr Pierre Raffin, OP, Paris 1996.

10. Prueba de ello es que hasta el presente se haya dividido el texto de muy distintas maneras: en $7,8,12,17$ y hasta 30 y 40 capítulos, titulados también de muy distintos modos (cf. L. RuBio, La norma fundamental, p. 194). El autor sostiene además que en cuanto a su estructura o especial ordenación, no será aún fácil obtener un consenso unánime ni respecto a las secciones y menos aún repecto a los parágrafos, ni tampoco respecto a los epígrafes. El problema está en que tal divergencia en las divisiones puede dar origen a deformaciones de sentido (ib.).

11. En adelante DVR.

12. En adelante C10. 


\section{LA ESTRUCTURA DE LA REGLA: NUESTRA PROPUESTA}

Pero antes procede presentar las propuestas adelantadas por otros estudiosos. En efecto, puesto que conocer la estructura de un escrito ayuda a comprenderlo, determinar la de la Regla ha sido frecuente preocupación de quienes han emprendido su estudio ${ }^{13}$. D. Sanchis opinaba que san Agustín no se había impuesto un plan estricto, algo que no estaba dentro de sus modos de actuar, añadiendo luego que eso no implicaba afirmar que la Regla se redujera a una juxtaposición de desarrollos sin otro lazo que un mismo tema general 14. Ya en concreto, A. Manrique se conforma con contraponer el capítulo primero como precepto fundamental a los restantes como preceptos particulares ${ }^{15}$. A. Trapè estructura su comentario sobre los siguientes elementos: fin del monacato (ante todo amad a Dios y al prójimo), medio (la unidad de almas y corazones), centro (la caridad que permanece); todo el resto lo considera como un presupuesto o un alimento o un motivo de inspiración ${ }^{16}$. Pero, aunque dichos elementos permitan una cierta estructuración lógica del contenido de la Regla, no responde evidentemente a la estructura del documento en cuanto tal. L. Rubio por su parte advierte en la Regla una ordenación de las secciones entre sí: $1^{a}$ ) norma fundamental de la vida monástica y su aplicación; $2^{a}$ ) de la oración; $3^{a}$ ) de la mortificación de la carne con ayunos y abstinencias; $4^{\mathrm{a}}$ ) comportamiento exterior y guarda de los sentidos, a la cual se yuxtaponen las normas de admonición, denuncia y corrección; $5^{\text {a }}$ ) prescripciones varias; $6^{a}$ ) cautelas contra las contiendas; $7^{\mathrm{a}}$ ) obediencia, función de los superiores y actitud entre súbitos y superiores ${ }^{17}$. En realidad no presenta más que un elenco de temas, sin particular concatenación lógica entre ellos.

Últimamente se ha ocupado también de la estructura de la Regla agustiniana el gran conocedor del monacato antiguo A. de Voguié. Este sabio hijo de san Benito opina que la estructura de la Regla se sostiene sobre dos prin-

13. Cf. D. SANCHIS, Pauvreté monastique et Charité fraternelle chez saint Augustin. Note sur le plan de la Règle, en Augustiniana 8 (1958) p. 10: «Renoncer a serrer de plus près le fil logique de sa démarche, serait sans doute nous priver des précieux lumières sur sa pensée ellemême.

14. $I b$.

15. Teología agustiniana..., pp. 362ss. A. Sage se queda en idéntica indeterminación: «Establecido el estatuto de la vida religiosa: vida de concordia basada en la práctica de la pobreza, san Agustín considera sus obligaciones fundamentales» (cf. La Regla, p. 55).

16. La Regola, pp. 95-96.

17. La norma fundamental, p. 194; también 192. 
cipios: el primero, la referencia al alimento y al vestido; el segundo, las tres virtudes que más tarde pasarán a constituir los tres votos específicos de la vida religiosa: castidad, pobreza y obediencia. Él mismo presenta el siguiente gráfico:
$1-3$
4-5
6-7
8

Exordio. Unanimidad

Alimento

Vestido

Castidad-Pobreza Obediencia Conclusión ${ }^{18}$

Estructura demasiado complicada que, además, tiene el inconveniente, como reconoce el mismo autor, de dejar de lado varias perícopas, entre ellas la referente a la oración (cap. $2^{\circ}$ ) y las contiendas (cap. $6^{\circ}$ ).

Del tema se ha ocupado también, y sobre todo, L. Verheijen. En sus escritos se advierten, al respecto, dos etapas con una ligera variante en la presentación de la estructura fundamental de la Regla. En la primera presentaba una estructura en cuatro partes: 1) Prefacio (R I,1 19); 2) Preceptos (R I,2-VII,4);3) el alma de todos los preceptos (R VIII,1); 4) «Postfacio» (R VIII,2) 20. En su opinión, esta estructura aún puede simplificarse más. En efecto, cabe reducir sus cuatro partes a la siguiente fórmula: por los praecepta uiuendi a la spiritalis pulchritudo ${ }^{21}$. Se trata de una estructura que él advierte ya en obras ante-

18. A. DE VoGÜÉ, Histoire littéraire du mouvement monastique dans l'antiquité, III, Paris 1996, pp. 177-178. El mismo reconoce que si el doblete alimento-vestido está claramente indicado, la tríada de las virtudes, de las cuales sólo la primera aparece señalada por su nombre $(I V, 4)$, puede parecer un reagrupamiento artificial, inspirado por categorías modernas. Pero de hecho, estas tres renuncias están asociadas varias veces por Agustín mismo, que las coloca siempre en el mismo orden: rechazo del matrimonio, de las riquezas, de los honores (cita DVR 5; De util. cred. 3; De Trin. 9,14). De ahí concluye que dicha terna está probablemente subyacente en la Regla, igual que el doblete alimento-vestidos.

19. La división en capítulos y parágrafos la tomamos de su edición crítica (La Régle de saint Augustin, I, pp. 417-437). De ella tomaremos también los textos.

20. Cf. «Vers la beauté spirituelle» (Par les praecepta uiuendi à la spiritalis pulchritudo. "Pythagore», le De Ordine de saint Augustin et sa Règle), en Augustiniana 22 (1972) 469-470; NA I, 201-202; L'Enarratio in psalmum 132 de saint Augustin et sa conception du monachisme, en Forma Futuri (Studi in onore del Cardinale Michele Pellegrino), Torino 1975, pp. 806-807; NA I,45-46.

21. Ib. 472; NA I, 204; Cf. Spiritualité et vie monastique chez saint Augustin, p. 94; NA I, 75-105; en concreto, p. 76. 
riores a la misma Regla, como el De ordine 2,8,25-19,51; Soliloquia 1,6,12; De quantitate animae 33,70ss 22. Detrás de la fórmula descubre a «Pitágoras», pero con una variante significativa. Mientras el principio «pitagórico» incluía un doble aspecto, el moral (pars vitae: praecepta vivendi) y el intelectual (pars eruditionis: disciplinae liberales), san Agustín se desprendió pronto del valor asignado a las disciplinas liberales ${ }^{23}$. En la segunda etapa introduce una variante; en vez de cuatro, habla ya de cinco partes 24: además de una breve introducción y una breve peroración, otras tres, que en adelante llamaremos «secciones».

En forma esquemática, he aquí la estructura del documento monástico tal como la presenta L. Verheijen:

a) Breve introducción (R I,1).

A) Principio fundamental: unidad de almas y corazones dirigidos hacia Dios (R I,2-8).

B) Aplicación del principio a los distintos aspectos de la vida de comunidad: aspectos comunitarios de la oración, la mesa común, las salidas y la salvaguarda mutua en el ámbito del celibato consagrado, los servicios comunitarios y la servicialidad fraterna, los eventuales conflictos, las relaciones entre el hermano «prior» y los demás hermanos (R II-VII).

C) Mirada hacia atrás que unifica y profundiza A y B (R VIII,1).

b) Breve peroración (R VIII,2) ${ }^{25}$.

Dicha estructura no la considera privativa de la Regla; a su parecer, constituye un modelo de composición al que recurre el santo si no habitualmente, sí con frecuencia. De hecho, las mismas etapas cree haberlas detectado en la

22. «Malgré l'évolution et l'approfondissement que la pensée d'Augustin a connus déjà dans les premiérs années après sa conversion, la structure essentielle de la Règle sera celle que nous avons rencontrée dans le De ordine et dans les Soliloquia, comme un peu plus tard, avec une magnifique précision, dans le De quantitate animae: par les praecepta uiuendi à la spiritalis pulchritudo» (Vers la beauté spirituelle, 484; NA I,216)

23. Ib. p. 469-510; NA I, 201-242.

24. Cinco partes que hace derivar de las cinco partes del discurso en el iudiciale genus, a saber: exordium, narratio, probatio, argumentatio, epilogus. Cf. Le De sancta virginitate, en Augustiniana 32 (1982) 269; NA II,181.

25 . Cf. Éléments d'un commentaire de la Rêgle de saint Augustin. XV. Comme amants de la beauté spirituelle. Dans Augustin évêque, en Augustiniana 32 (1982) 88-136; en concreto, p. 91-92; NA II,120-122; Le De sancta Virginitate de saint Augustin et sa estructure. Un complémente à l'étude du chapitre quatrième, en Augustiniana 32 (1982) 266-281, en concreto, p. $267-$ 268; NA II, 179-180; Le monachisme de saint Augustín, en Augustin, le message de la foi, Paris 1987, p. 63-69, en concreto, p. 70; NA II, p. 20. 
obra De sancta virginitate, el De opere monachorum, libros IV y VI de las Confessiones y el primer libro de De doctrina christiana ${ }^{26}$. Por otra parte, esa estructura ha sido aceptada sin dificultad por diversos autores ${ }^{27}$.

El hecho de abordar de nuevo la cuestión estructural no implica en absoluto poner en cuarentena el planteamiento general de L. Verheijen; al contrario, lo damos por supuesto. Pero nada hay perfecto en este mundo, y todo lo humano es susceptible de mejora. Reconocemos que no deja de ser una osadía pretender corregir al maestro, unánimemente reconocido a nivel mundial, en cuanto se refiere al monacato y Regla de san Agustín. Pero tenemos la seguridad de que él, desde la compañía de Dios, aprobará el que se intente mejorar sus propios e inmensos logros. En efecto, nuestra investigación se presenta sobre todo como un diálogo con el maestro, que sigue hablando en sus publicaciones. Diálogo vivo en que unas veces compartimos sus puntos de vista, otras se los discutimos, otras sólo pretendemos hacer la aplicación de intuiciones suyas o, lo que es lo mismo, sacar las conclusiones de premisas puestas por él.

Como acabamos de indicar, la estructura propuesta por L. Verheijen para la Regla es nuestro punto de partida. Consideramos que responde a la reali-

26. Cf. Le De sancta Virginitate de saint Augustin et sa estructure. Un complémente à l'étude du chapitre quatrième, en Augustiniana 32 (1982) 266-281; NA II, 178-193; Les Confessions de saint Augustin. Deux grilles de composition et de lecture. Paris, Association sacerdotale «Lumen gentium», cahier n 115 (1987) 15-22; NA 106-113; Le monachisme de saint Augustín, en Augustin, le message de la foi, Paris 1987, p. 63-69, en concreto, p. 70; NA II, p. 20; Le première livre du De doctrina christiana. Un traité de "telicologie" bíblique, en Augustiniana Traiectina. Communications presentées au Colloque internationel d'Utrecht. 13-14 novembre 1986, éditées par J. van der Boeft et J. van der Oort, Paris 1987, 169-187; en concreto, p. 185.

27. Cf. p. ej., T. van Bavel (Regla para la Comunidad, p. 31), A. Zumkeller (Ein grundlegendes Werk über die Augustinusregel, en Augustininianum 9 [1969] 145-149); G.M. Colombás (La Tradición benedictina I, Zamora 1989, p. 404). A ella se reduce también la presentada por Sor Marie-Ancilla. Esta monja dominica propone la siguiente estructura: 1. Exordio. 2. Prefacio (cap. 1,1); 3. Unidad de almas y corazones (cap. 1,2-8, que constituye la clef de voûte de la Regla); 4. La vida del monasterio, vista a la luz de Hech 4,32-35 (cap. 2-7); 5. La conclusión (cap. 8). La subdivisión que establece en la parte 4. sigue un criterio puramente material (La Règle de saint Augustin, p. 61-62). El exordio se refiere a las palabras: «Ante omnia, fratres carissimi, diligatur Deus, deinde et proximus, quia ista sunt praecepta principaliter nobis data». Ha de tenerse en cuenta que la monja dominica comenta la Regula recepta, esto es, la Regla tal como se lee en las Órdenes y Congregaciones religiosas que la han asumido como norma de vida. Dicha Regula recepta coincide con el Praeceptum mismo, pero precedido del primer párrafo del Ordo Monasterii -el texto citado-, la primera Regla monástica surgida en occidente, que algunos atribuyen a san Agustín mismo y todos, al menos, al entorno del santo. Sobre esta Regla, cf. L. Verheijen, La Règle..., II, 125-174. Sobre la Regula recepta, ib., II, 114124. Sobre el Ordo Monasterii hablaremos también en otra parte de este trabajo. 
dad del documento, pero que es genérica en exceso. Diríamos que se limita a mostrar lo que se ve desde el exterior. Siguiendo con la imagen empleada al principio, para conocer la estructura global de un edificio es preciso entrar dentro de él, porque también los interiores están gobernados por una estructura particular. Sin descubrir la estructura de tales interiores, no se puede pretender conocer el edificio en su totalidad. Lo mismo vale para la Regla, tanto en la sección $\mathrm{B}$ como en la $\mathrm{C}$, que son las que nos ocuparán.

La sección $\mathrm{B}$, que incluye seis capítulos - del segundo al séptimo, ambos inclusive-, es presentada por el sabio agustino holandés como la aplicación del principio fundamental formulado en el primero a los distintos aspectos de la vida de comunidad. Pero no entra en más detalles ni establece división interna alguna. Ahora bien, no es fácil pensar que esta sección no esté regulada por algunos otros principios. Absolutamente considerada, es pequeña en extensión, sí; pero no se debe olvidar que representa el $80 \%$ del texto de la Regla y en ese sentido relativo es suficientemente extensa para suponer en ella alguna subdivisión. Es más, nos parece conforme a la realidad del texto dividir la sección en tres unidades. La primera correspondiente al capítulo segundo; la segunda, a los capítulos tercero y cuarto; la tercera, a los capítulos quinto, sexto y séptimo. Cada una de estas unidades tiene en el trasfondo una de las tres concupiscencias mencionadas por san Juan (cf. $1 \mathrm{Jn} 2,16$ ) y una de las tres obras reclamadas por Jesús en el Sermón de la montaña (cf. Mt 6) a sus seguidores: la primera, la concupiscencia de los ojos y la oración; la segunda, la concupiscencia de la carne y el ayuno; la tercera, la ambición mundana y la limosna. En forma esquemática, he aquí la estructura interior que proponemos para esta sección B:

Unidad primera: concupiscencia de los ojos/oración (R II).

Unidad segunda: concupiscencia de la carne/ayuno (R III-IV).

Unidad tercera: ambición mundana/limosna (R V-VII).

Más adelante desglosaremos, a su vez, en distintos elementos las unidades segunda y tercerâ.

Y pasamos ya a la tercera sección (C). En la estructura propuesta por L. Verheijen, corresponde a la primera mitad del capítulo octavo.

El texto del capítulo es el siguiente en traducción española:

«Que el Señor os conceda observar todo esto con amor, como enamorados de la belleza espiritual e inflamados por el buen olor de Cristo que desprende una vida santa, no como siervos bajo la ley, sino como personas libres bajo la gracia» (VIII,1). 
El docto agustino presenta esta sección como una mirada hacia atrás que engloba y profundiza lo dicho en las otras dos etapas (A y B) o, con otras palabras, como el alma de todo este cuerpo de prescripciones y prohibiciones ${ }^{28}$; pero lo engloba sin resumirlo, sin repetirlo brevemente o decirlo con otras palabras, abriendo así las perspectivas más vastas y elevadas de todo el documento; su brevedad se corresponde con su profundidad ${ }^{29}$. Lo juzga como un pasaje compacto en el que cada palabra tiene su peso, un punto fuerte del texto ${ }^{30}$, donde se encuentran los pensamientos más importantes, las simplificaciones más esenciales y donde el Santo «va a remachar el clavo» 31. Según él, representa la cima de la Regla, en cuanto que expresa la orientación propia de toda la parte preceptiva anterior y sitúa los preceptos en sus perspectivas fundamentales: no en un clima de servilismo, sino de amor, en un ambiente de contemplación y amor, con referencia continua a Cristo en un espíritu de libertad cristiana ${ }^{32}$.

Esta sección es, pues altamente ponderada por el sabio agustino; le asigna una gran importancia, la máxima en el conjunto de la Regla 33. Pero también tenemos objeciones que oponerle. En efecto, de un lado, no distingue entre la relación que pueda tener con la sección A de la que pueda tener con la sección B y, de otro, no percibe división interna alguna, aunque aquí es más comprensible, dada la extrema brevedad del pasaje.

A nuestro parecer, el texto lo configuran dos principios: uno unificador y otro diversificador. El elemento unificador es objetivo: el cumplimiento, por obra del amor, de las prescripciones anteriores. El diversificador es subjetivo: tres son, efectivamente, las actitudes personales desde las que es posible el

28. L'Enarratio in psalmum 132, p. 806-807; NA I,45-46; Le monachisme, p. 71; NA II, 21.

29. Le De sancta virginitate, 268; NA II, 180.

30. Comme amants de la beauté spirituelle. Dans Augustin évêque, en Augustiniana 32 (1982) 93-94; NA II,122-123; Les Confessions..., p. 15; NA II, 107 («lejos de ser un apéndice despreciable, me parece que es una parte capital, aun siendo breve»).

31. Le première livre du De doctrina christiana, p. 185.

32. La Loi et la grâce p. 77; NA I, p. 59); Spiritualité et vie monastique, p. 94.96; NA I, 76.78; Le monachisme, p. 73; NA II,23 («va hasta el fondo de su proyecto»); La spiritualité de saint Augustin et la nôtre, en NA II, 32 («nos hallamos aquí en una de las cimas del escrito»).

33. En el ponderar esta parte no está sólo. Cf., p. ej., G. M. Colombás: «termina el Praeceptum con estas maravillosas palabras, $\tan$ agustinianas y tan profundamente cristianas» (La tradición benedictina, I, p. 411); A. Trapè, que ve en la sección los motivos inspiradores de la vida común, habla de «un período denso de pensamiento y de puro meollo agustiniano» (La regola, p.111). 
cumplimiento de lo ordenado. Por ello, lo desglosamos de la siguiente manera:

Principio unificador, el amor:

«Que el Señor os conceda observar todos estos preceptos con amor» (Donet Dominus, ut obseruetis haec omnia cum dilectione) (R VIII,1a).

Principio diversificador o distintas actitudes personales:

a) como enamorados de la belleza espiritual (R VIII,1b).

b) como inflamados por el buen olor de Cristo que desprende una vida santa (R VIII,1c).

c) no como siervos bajo la ley, sino como personas libres bajo la gracia ( $R$ VIII,1d).

En latín:

a) tamquam spiritalis pulchritudinis amatores (R VIII,1b).

b) et [tamquam] bono Christi odore de bona conversatione flagrantes ( $\mathrm{R}$ VIII,1c).

c) non sicut serui sub lege, sed sicut liberi sub gratia constituti (R VIII,1d) ${ }^{34}$.

L. Verheijen no parece haber dado importancia a esta diversificación de actitudes personales. Su interés se centra en el primer punto («enamorados de la belleza espiritual»), como si incluyese todos los demás. Recordemos la estructura de la Regla, reducida a su máxima simplicidad, que él proponía: «se trata 1) de praecepta vivendi que 2) han de ser observados con amor por la belleza espiritual» ${ }^{35}$. El punto 1), por lo genérico de los praecepta vivendi, puede entenderse que sintetiza bien los capítulos anteriores de la Regla; no así el 2), que sólo hace referencia a la primera de las tres actitudes, olvidando las otras dos que aparecen en el texto con idéntico valor que la primera. Signo de la importancia que asigna a la primera es el hecho de que dedicó tres interesantes artículos a estudiar la belleza espiritual en san Agustín 36. La segunda actitud le pasa casi desapercibida; apenas le dedica algunas referencias,

34. El cambio del tamquam por el sicut en c) obedece sin duda a motivos puramente literarios, para obtener la variatio.

35. Cf nota 21. Ya L. Cilleruelo le criticaba señalando que «parece infantil dividir la Regla en dos partes: una formada por tres palabras (spiritalis pulchritudinis amatores) y otra por todo el resto» (cf. La evolución del monacato agustiniano, en Estudio Agustiniano 15 (1980) p. 175, n. 17).

36. Vers la beauté spirituelle; Comme des amants de la beauté spirituelle. Dans Augustin évêque; Comme des amants de la beauté spirituelle. Dans les oeuvres du jeune Augustin. 
pero siempre de forma muy genérica, sin concederle valor autónomo ${ }^{37}$. El tercero punto sí ha sido objeto de su interés y estudio y le ha dedicado un artículo, pero en cuanto criterio para establecer la fecha de composición de la Regla 38 .

A la luz de lo establecido para la sección segunda (B) de la Regla, aun dentro de la brevedad del párrafo, proponemos una división tripartita. Según ella, cada una de las actitudes personales se corresponde con una de las unidades allí señaladas:

a) El «enamorados de la belleza espiritual» se corresponde con la primera «unidad» (R II), esto es, hace referencia a la concupiscencia de los ojos y a la oración.

b) El «inflamados por el buen olor de Cristo» se corresponde con la segunda unidad (R III-IV), esto es, hace referencia a la concupiscencia de la carne y al ayuno.

c) El «libres bajo la gracia» se corresponde con la tercera unidad (R VVII), esto es, hace referencia a la ambición mundana y a la limosna.

Formulado esquemáticamente tendríamos, pues:

Concupiscencia de los ojos/oración:

Sección B: R II. Sección C: R VIII,1b ${ }^{39}$.

Concupiscencia de la carne/ayuno:

Sección B: R III-IV Sección C: R VIII,1c

Ambición mundanallimosna:

Sección B: R V-VII Sección C: R VIII,1d

Gráficamente se puede presentar de la siguiente manera:

37. Comme des amants de la beauté spirituelle. Dans Augustin évêque, p. 92; NA II, 121: «No en un clima de legalismo, sino de amor, en un ambiente de contemplación y de oración, con una referencia continua a Cristo en un espíritu de libertad cristiana" (Spiritualité et vie monastique. p. 94; NA I,76). En cambio, véase cómo resume las perspectivas fundamentales recogidas en esa sección $\mathrm{C}$ en otro artículo: «con amor, libremente..., como amantes de la belleza espiritual» (La Loi et la grâce..., 77; NA I, 59). Aquí desaparece por completo de la mente del autor. En otros textos, une $1 \mathrm{~b}$ y $1 \mathrm{c}$ como si la belleza espiritual fuese precisamente la de las virtudes que desprenden el buen olor de Cristo.

38. La Loi et la grâce. La «date ancienne» et la «date récente» de la Règle (cf. nota 1). Cfr. Comme des amants de la beauté spirituelle. Dans Augustin évêque, p. 94ss; NA II, 123ss. 


\section{A: EL DESEO PLENIFICADO B: EL DESEO “PERVERTIDO" C: EL DESEO RECTIFICADO}

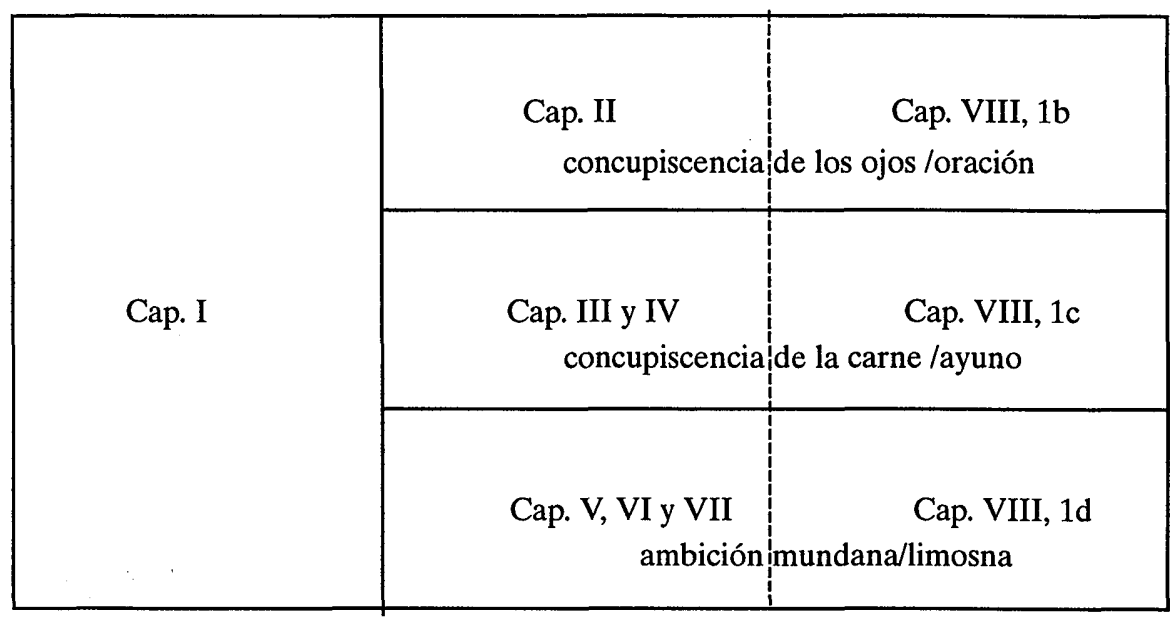

. ESQUEMA 1

Tal es, a nuestro parecer, la estructura interior de la Regla. Ahora sólo queda probar la verdad de lo afirmado.

\section{LAS PREMISAS}

3.1. En repetidas ocasiones señala san Agustín la existencia de tres categorías de cristianós: los clérigos o ministros de la Iglesia, los siervos de Dios o monjes y los laicos. Cada una de esas categorías la encuentra figurada en santos varones del Antiguo Testamento: Noé, Daniel y Job, respectivamente 40 . La relación entre las diversas categorías y los personajes se fundamenta en las circunstancias personales de éstos. Noé es figura de los ministros porque éstos gobiernan a la Iglesia en medio del mar de este mundo, como él gobernó el arca durante el diluvio; Job simboliza a los laicos porque, como ellos, tenía

40. Cf. Enarrationes in psalmos 36,1,2; 99,13; 132,4-5; Quaest. evang. I,12; II,44; Epistula 111,4; De urbis excidio 1,1; De pecc. meritis et remissione II,10,12. Véase P. LANGA, «La trilogía Noé-Daniel-Job", en Obras Completas de San Agustín XXXIV, BAC 541, p. 784, nota complementaria 15 , con la bibliografía respectiva; por error tipográfico sin duda, aparece la Epistula 3, en vez de la 111; y Quaest. evang. II,14, en vez de II,44. 
posesiones e hijos; Daniel simboliza a los siervos de Dios porque, como ellos también, eligió la vida tranquila (uitam quietam) y servir a Dios en el celibato.

En ese mismo contexto, en el Comentario al salmo 132, uno de los pasajes en que expone más claramente su ideal monástico, el santo añade significativamente que Daniel fue llamado uir desideriorum, varón de deseos (Dn 10,11). A partir de esta constatación se puede comprender el importante papel asignado al deseo en la vida monástica agustiniana. Conviene, no olvidar, sin embargo, que como tal denominación le resultaba ambigua, se vio obligado a precisar de qué deseos se refería: a los deseos celestes, deseos castos y santos ${ }^{41}$. Por otra parte, el deseo es un punto crucial de la teología y espiritualidad agustinianas. Pero antes es un concepto clave de su antropología 42. De aquí la oportunidad de detenernos un poco en la consideración de las distintas clases de deseos que anidan en el corazón del hombre.

3.2. Como punto de partida tomamos el último capítulo del libro primero de las Confessiones. Allí san Agustín enumera y agradece a Dios los dones que recibió de Él en su niñez, a la vez que reconoce su pecado e indica en qué consistió. Pero antes de citar el texto y comentarlo juzgamos conveniente hacer referencia a un artículo, ya citado ${ }^{43}$, de L. Verheijen, cuyas conclusiones nos servirán de ayuda.

Tras examinar el término confessio en las Confessiones, el sabio agustino concluye que encierra un triple aspecto doble. Con estas palabras compendia los resultados de su análisis:

«En síntesis, sinfonía de miseria humana y de misericordia divina; sinfonía correspondiente de confesiones, de alabanzas y de acciones de gracias; y todo esto en un triple dominio: nada/ser; tinieblas/luz; pecado/santidad (en progresión hacia la salud definitiva y eterna» ${ }^{44}$.

41. Enarratio in psalmum 132,5: CC 40,1929-1930: «Daniel uitam quietam elegit, in coelibatu seruire Deo, id est, uxorem non quaerens. Erat uir sanctus, in desideriis caelestibus uitam gerens; tentatus in multis, et inuentum aurum obrizum. Quam quietus erat, qui et inter leones securus erat. Ergo in nomine Danielis, qui etiam uir desideriorum est appellatus (Dn $10,10)$, sed utique castorum atque sanctorum, significantur serui Dei, de quibus dicitur: Ecce quam bonum et quam iocundum habitare fratres in unum (Sal 132,1)».

42. Cf. I. Bochet, Saint Augustin et la désir de Dieu, Paris 1982; M. ROSENBERgER, Der Weg des Lebens. Zum Zusammenhang von Christologie und Spiritualität in der Verkündigung des Hl. Augustinus, Regensburg 1996, 124ss.

43. Les Confessions (cf. nota 26).

44. Les Confessions, p. 7; NA II,98. Añadimos otra formulación de lo mismo: «En efecto, sea a modo de conclusión, sea a modo de programa, Agustín ha indicado repetidamente bajo qué luz quería colocar los diferentes temas sobre los que hacer su «confesión», y cada vez 


\section{Y continúa:}

«El confesante, pues, se coloca ante un Dios que él considera como fuente del ser, como fuente de la luz intelectual y espiritual, como fuente de buena conducta moral. ¿Cómo no reconocer en esta terna la tripartición de la filosofía que Agustín ha atribuido a Platón y que describe en La ciudad de Dios 8,3-10 y $11,25 ? » 45$.

Dicha terna le lleva, a su vez, a Conf. 13,11,12 donde san Agustín pone en relación la terna esse, nosse, velle con la Trinidad. Lo que nos interesa ahora son las relaciones entre la tripartición de la filosofía «de Platón», la tripartición de la perspectiva de Agustín en su confessio y la tripartición de las materias de que el confesante habla a Dios ${ }^{46}$.

Disponemos, pues, del contexto filosófico 47 en que se coloca el pasaje que vamos a citar y comentar brevemente. Es el siguiente:

subraya que ve por doquier una sinfonía de la «miseria» de la criatura, sobre todo de la criatura humana, y de la misericordia de Dios, que se inclina sobre esta indigencia (nada, pecado, ignorancia)». «Por doquier Agustín ha querido, muy conscientemente, hablar, con acentos diversos, de la misericordia de Dios hacia la miseria humana, y estos en los tres dominios del ser, del conocer y del obrar moral, que están todos dirigidos hacia la salud definitiva, universal y eterna" (Ib., p. 11.13; NA II, 102.104).

45. Les Confessions... p. 7; NA II, 98. He aquí algunos de los textos a que hace referencia: «Se alaba a Platón porque, habiendo unido a ambos (Sócrates y Pitágoras), llevando así a la perfección la filosofía que dividió en tres partes: la moral, que se refiere sobre todo a la acción; la natural, que se relaciona con la contemplación y la racional que distingue lo verdadero de lo falso... Quizá ellos (los discípulos de Platón) piensen, respecto de Dios, que en Él se encuentra la causa de la subsistencia, y la razón de la inteligencia y la regla de vida; de estos tres aspectos, uno se refiere a la parte natural de la filosofía, otro a la racional y el tercero a la moral. Pues si el hombre fue creado en tal condición que, por lo que en él hay de más excelente, puede alcanzar al Ser superior a todos los seres, es decir, el único Dios verdadero y perfecto, sin el cual no subsiste naturaleza alguna, ni instruye doctrina alguna, ni aprovecha costumbre alguna: busque a aquel en quien encontramos connexas todas las cosas; contemple a aquel en quien todas las cosas son ciertas; ame a aquel en quien tenemos la suprema rectitud» (De civitate Dei 8,4). Y más adelante: «La primera parte fue llamada Física, la segunda Lógica, la tercera Ética (nombres que tienen como correspondientes latinos en los escritos de numerosos autores, parte natural, racional y moral...). No se sigue que estos filósofos (los platónicos) hayan tenido en esta tríada idea alguna de la Trinidad en cuanto Dios, aunque se dice que Platón fue el primero en descubrir y recomendar esta distribución, y que no hubo para él otro autor de las naturalezas sino Dios, ni otro dador de la inteligencia, ni otro inspirador del amor, que hace vivir bien y felizmente» $(i b .11,25)$.

46. Cf. Les Confessions... p. 8; NA II, 99.

47. No importa que Agustín atribuya a Platón esa tripartición de la filosofía porque «la description qu'Augustin donne de la philosophie de Platon dans la Cité de Dieu est plutôt une description de la philosophie d'Augustin lui même»; ni debe importar la cuestión cronológica, 
«Se fortalecía mi memoria, me equipaba con el habla, disfrutaba con la amistad; huía del dolor, abyección e ignorancia. ¿Qué hay en un viviente como este que no sea digno de admiración y alabanza? Pues todas estas cosas son dones de mi Dios, que yo no me los he dado a mí mismo. Y todos son buenos y todos ellos soy yo... En lo que pecaba yo entonces era en buscar en mí mismo y en las demás criaturas, no en Él, los deleites, grandezas y verdades, por lo que caía luego en dolores, confusiones y errores. Gracias a Ti, dulzura mía, gloria mía, confianza mía y Dios mío, gracias a Ti por tus dones; pero guárdamelos Tú para mí. Así me guardarás también a mí y se aumentarán y perfeccionarán los que me diste, y yo seré contigo porque Tú me diste que existiera» 48 .

El texto comienza haciendo mención de una terna de dones que Dios otorgó al niño Agustín. Una terna presentada primero en versión positiva: el vigor de la memoria, el mejor conocimiento del lenguaje, el disfrute de la amistad. En su versión negativa se manifiesta en un triple rechazo: del dolor, de la abyección y de la ignorancia.

Respecto de dichos dones, se imponen algunas consideraciones. La primera, que no son algo accidental al niño o a la persona humana; son constitutivos de su mismo ser. El santo no podía ser más explícito en su afirmación: «todos esos dones son buenos y todos ellos soy yo». La segunda, que cada uno de esos dones hace referencia a una de las tres partes de la filosofía: el vigor de la memoria, así como el rehuir el dolor corresponden a la filosofía natural; el mejor conocimiento del lenguaje y la repulsa de la ignorancia, a la filosofía racional; por último, el disfrute de la amistad y el repudio de la abyección, a la filosofía moral. La tercera, que tales dones los recibe el hombre en grado incoativo; de hecho están orientados a acrecentarse y plenificarse 49; de ahí que se constituyan en fuente de un triple deseo ${ }^{50}$. El santo habla de su búsqueda de deleites, grandezas y verdades, en referencia asimismo a la filosofía

porque ya en Contra Academicos había atribuido á Platón la división de la filosofía en moralia, naturalia y dialectica (Les Confessions... p. 7; NA II, 98).

48. «... memoria uigebam, locutione instruebar, amicitia mulcebar, fugieban dolorem, abiectionem, ignorantiam. Quid in tali animante non mirabile atque laudabile? At ista omnia dei mei dona sunt. Non mihi ego dedi haec: et bona sunt et haec omnia ego.... Hoc enim peccabam quod non in ipso, sed in creaturis eius me atque ceteris uoluptates, sublimitates, ueritates quaerebam, atque ita inruebam in dolores, confusiones, errores. Gratias tibi, dulcedo mea et honor meus et fiducia mea, deus meus, gratias tibi de donis tuis; sed tu mihi ea serua. Ita enim seruabis me, et augebuntur et perficientur quae dedisti mihi, et ero ipse tecum, quia et ut sim tu dedisti mihi» (Conf 1,20,31: CC 27,17). rior).

49. «... así se aumentarán y perfeccionarán» (cf. fin del texto recogido en la nota ante-

50. Agustín no emplea aquí el término deseo, pero la realidad está clara bajo el verbo buscar y, antes, negativamente, huir. 
natural, moral y racional respectivamente. Estos deseos son la fuerza dinamizadora de la existencia humana en sus diversas facetas. De hecho, significan la aspiración a la plenitud de aquello mismo de que el hombre participa incoativamente. La satisfacción de tales deseos sólo es posible en Dios quien, de una parte, le ha infundido el deseo al otorgarle el don en grado incipiente $\mathrm{y}$, de otra, representa la plenitud a que aspira.

En el caso de Agustín, como en el de cualquier hombre, el pecado se introdujo como elemento perturbador e impidió la satisfacción en Dios de los mencionados deseos. En efecto, como consecuencia del mismo, el hombre los orientó en una dirección equivocada. Tal es la «perversión» del deseo, que consistió en buscar en sí mismo y en las demás criaturas y no en Dios la satisfacción de su ansia de deleite, de grandeza y de verdad. Perversión causante de una situación lamentable, que dejó sus huellas devastadoras. Con referencia al joven Agustín, se puede afirmar que le salió cara, pues le proporcionó dolor, confusión y error, exactamente lo contrario de lo que buscaba. Pero, afortunadamente, hubo lugar también para la reorientación del deseo. Decir que la historia personal de Agustín, que el texto citado recapitula, acaba abierta a la esperanza es decir poco. Cuando el santo lo escribe, lo hace desde la experiencia de que las tinieblas de la «perversión», del extravío, han pasado y brilla para él ya la luz en el camino reencontrado. Dios se le ha manifestado ya como su'dulzura, su gloria y su confianza.

Se puede hablar, pues, de tres etapas del deseo: en la primera está orientado hacia Dios; en la segunda se halla «pervertido» o extraviado lejos de Dios; en la tercera vuelve a ser orientado hacia Él. Todas estas etapas son recorribles en la existencia terrena. A ellas puede añadirse una cuarta: la del deseo plenificado en Dios, que pertenece ya a la plenitud escatológica.

3.3. Con vistas a nuestro objetivo, hemos de volver a la etapa de la «perversión» del deseo. Esta tiene su mejor expresión en la terna de pasiones ${ }^{51}$ a

51. El origen de este esquema triádico, que, según O. Du Roy, quizá haya que poner en relación con las tres partes del alma de la filosofía platónica: la racional, la irascible y la concupiscible (L'intelligence de la foi en la Trinité selon saint Augustin. Genêse de sa théologie trinitaire jusqu'en 391, Paris 1966, p. 344,3), no está claro. Se podría pensar que el santo lo tomó de san Juan, pero no resulta fácil probarlo. Dè hecho, su formulación conforme a $1 \mathrm{Jn}$ 2,16 en Agustín sólo se va imponiendo con el pasar del tiempo. W. Theiler pensaba que lo había tomado de Porfirio. La propuesta, tomada en consideración por I. Bochet (cf. Animae Medicinae: La libération de la triple convoitise selon le De vera religione, en Il mistero del male e la libertà possibile (IV): Ripensare Agostino. Atti dell'VIII Seminario del Centro Studi Agostiniani di Perugia, a cura di Luigi Alici, Remo Piccolomini, Antonio Pieretti (Studia Ephemeridis Augustinianum 59), Roma 1997, p. 154, n. 54), fue rechazada por O. Du Roy por no presentar 
que hace referencia san Juan (1 Jn 2,16). San Agustín suele designarlas, sirviéndose del texto de la carta apostólica, como concupiscencia de la carne, concupiscencia de los ojos y ambición mundana (secular) ${ }^{52}$, pero no siempre; los nombres varían con frecuencia según los textos ${ }^{53}$. Ha de tenerse en cuenta, por otra parte, que cada una de las tres concupiscencias representa la inversión de la dependencia del hombre respecto de cada una de las tres personas divinas; la inversión de las tres relaciones constitutivas del ser creado 54 .

Concedemos especial importancia al hecho de que la terna de las tres concupiscencias esté siempre a flor de labios o a punta de pluma en el Santo. A. Labhardt señala la obsesión por esa tríada de pasiones en el pensamiento de san Agustín hasta en los sermones ${ }^{55}$. Sobre todo en la primera parte de su vida que sigue a la conversión, pero no exclusivamente. Su desarrollo más amplio nos lo ofrece en dos obras: DVR 38,69-55,107, compuesta hacia el 390, y C10 $(29,40-39,64)$, escritas entre el 397 y el 40056 . A ellas hay que añadir, por criterio de extensión, los Tractatus in Iohannis epistulam 2,9-14 (del 407) 57.

ningún texto concluyente. Según este autor, quizá se trate de un tema filosófico anterior, complementado con la cita bíblica y con la participación del genio de Agustín, bien capaz de crear esquemas nuevos y de sintetizar los que pudiera encontrar. Considera probable que la tríada haya preexistido, pero que el uso que de ella hace Agustín sea original y esté profundamente marcado por su ingenio propio. Basta seguir la evolución y la sistematización para constatarlo (Cf. L'intelligence de la foi, pp. 243-263).

52. Lo cual no obsta para que en In epistulam Johannis ad Parthos tractatus 2,12-14 emplee el término desiderium en vez de concupiscentia.

53. Cf. por ej., DVR 38,69-71: CC 32,232-234, donde encontramos, además de la ya indicada de san Juan, esta cupiditas uoluptatis, uel excellentiae, uel spectaculi; o esta otra: libido, superbia, curiositas. Para otras designaciones, cf. nota 56.

54. Cf. O. Du Roy, L'intelligence de la foi, p. 343. 352-353. 355. 362. 364. 365.

55. Curiositas. Notes sur l'histoire d'un mot et d'une notion, en Museum Helveticum 17 (1960) 222, citado por O. Du Roy en L'Intelligence de la foi..., p. 344, n. 2.

56. Téngase en cuenta que la sección señalada de DVR aparece encorchetada con la cita de 1 Jn 2,16. Por otra parte, la terna de pasiones o concupiscencias no sólo aparece en el pasaje indicado, sino también en otros anteriores. Helas aquí, con el término latino que alude a cada una de ellas: 10,18: CC 32,199 (colere animam, corpus, phantasmata); 34,64:229 (sensibus c., consuetudine $h$., laudibus $h$.), y otras en que la avaricia sustituye a la concupiscencia de los ojos, a saber, 3,5:191 (caste, desertis diuitiis, honoribus); 16,31:206 (diuitias, honoribus, carnales filios).

En la Confesiones aparece también en otros numerosos pasajes, además del libro décimo: 1,10,16: CC 27,9 (uictorias, aures, curiositas); 1,19,30: 16-17 (spectandi, gula, excellentiae); 1,20,31: 17 (dolor, abiectio, ignorantia; dolor, confusiones, errores; uoluptates, sublimitas, ueritas; dulcedo, honor, fiducia; 2,5,10: 22 (species, congruentia, decus); 3,1,1-3,6: 27-29 (libido, spectacula, excellere); 3,8,16:35-36 (libido principandi, l. spectandi, l. sentiendi); 4,1,1: 40 (gloria, spectacula, libidines); 4,2,2-3: 40-41 (cupiditas, libido, superstitio); 5,3,5: 59 (exaltationes, 
3.4. El deseo «pervertido» se manifiesta, pues, en la triple concupiscencia, por la que el hombre busca fuera de Dios lo que sólo en Él puede hallar en la plenitud anhelada. Pero el hombre tiene la posibilidad de reorientar dicho deseo en su justa dirección, esto es, hacia Dios. No por sí mismo, sino por mediación de Jesucristo. De hecho, ya desde sus primeros escritos, san Agustín suele presentarlo en esa función. Jesucristo vence la tentación que significa cada una de las concupiscencias y señala la nueva dirección que ha de tomar el deseo del hombre 58 . Veamos ahora sólo algunos ejemplos 59 .

3.4.1. Un primer texto lo encontramos en la obra De genesi aduersus manichaeos, escrita en Tagaste hacia el 389.

En el capítulo 33 del primer libro, el santo establece una comparación entre los siete días de la creación y las siete edades del mundo. Sostiene que la predicación del Señor da fin al quinto día y comienzo al sexto en que aparece la senectud del hombre viejo. Se trata de una edad en que el reino «car-

curiositates, luxuriae); 9,1,1: 133 (uoluptas, lux, honor; dulcior, clarior, sublimior); 13,21,30: 259 (superbia, luxuria, scientia); 13,23,33: 261 (piscium, uolatilium, pecorum-ferarum). A ellas habría que añadir otras ternas en que, el lugar de la «concupiscencia de los ojos», es ocupado por la avaricia: cf. 2,5,11: 22-23 (coniugem, praedium, ulcisci); 6,6,9: 133 (honores, lucri, coniugium); 6,11,19: 87 (honor, uxor, pecunia); 9,1,1: 133 (ambiendi, adquirendi, uolutandi; claritas, diuitiae, salus).

57. Aunque los textos señalados ofrezcan los comentarios más amplios a la tríada, conviene no olvidar que hay otros muchos que, al menos, la mencionan brevemente en una formulación u otra. Con anterioridad al DVR la tríada aparece en De moribus eclesiae I 15,25; 19,36; 21,38-39: ed. J.K.Koyle, p. 278; 283; 284-285; De genesi adversus manichaeos I 23,40; 2 2,26,40: PL 34,192.217 (del 389), De musica VI,13,39: PL 32, 1184 (del 390 [Aunque al respecto hay que contar con la posibilidad de que el libro VI haya sido revisado varios años más tarde]). Inmediatamente después del DVR, la encontramos en De libero arbitrio II 19,53 (199) CC 29,272 (del 391); De duabus animabus 9: CC CSEL 25/1,62; Enarrationes in psalmos 7,9; 8,13; 9,8: CC 38,43.55-57.62 (del 392); Epist. 27,2-3: CSEL 34/1,97-98ss. Ya en la órbita cronológica de las Confessiones contamos con Sermo 284,5: PL 38,1291-1292 (en la hipótesis de que haya sido predicado en el 397; cf. nota 67); De agone christiano 6,6: PL 40,294; De catechizandis rudibus 27,55: CC 46,177-178 (del 404); Quaestiones evangeliorum II 47: PL 35,1332 (del 400); Sermo 313 A (Denis 14),2: MA I,66-67 (del 401 o antes); Sermo 311,6,6: PL 38,1416 (del 405). Con posterioridad a los Tractatus in Iohannis epistulam y a cierta distancia la encontramos en Sermo 335 B (Guelf 31),4 (del 410-412); Sermo 112: RBén 76 (1966) 44-54 (del 411 al 420), De Trinitate XII,9,14: CC 50,368-369; Epistula 145,2: CSEL 44,267; Sermo 96,4,4-7,7: PL 38,586-588 (del 416-417); De ciuitate Dei XII,1,2; XXI,16: CC 48,355.782. Sin fecha, Sermones 9,18 y 17,2: Cं $41,143-144.238$.

Cf. el cuadro presentado por O. Du Roy, en L'intelligence de la foi... pp. 351, nota 1.

58. Este es, podríamos decir, el reverso de la moneda; el anverso hay que verlo en la presentación de Cristo como aquel que realiza las tres partes de la filosofía, física, ética y lógica. $\mathrm{Al}$ respecto véase el artículo de I. Bochet, citado en tota 51.

59. Otros irán saliendo a lo largo del estudio. 
nal» sufre una violenta sacudida, pues se derriba el templo y cesan los sacrificios. Pero, a la vez que el hombre viejo camina hacia el fin de su vida, nace el nuevo que ya vive del espíritu. Si en el día quinto Dios había ordenado a las aguas que produjesen reptiles de almas vivas (cf. Gen 1,20-23), en el sexto ordenó a la tierra que produjese ese alma viva (Gen 1,24-25), gracias a la cual se comienzan a desear los bienes eternos. Los reptiles de almas vivas son símbolo de los judíos en medio de los gentiles, el alma viva es figura de quienes iban a creer de forma estable en el evangelio. Además, si en el sexto día creó Dios al hombre a imagen y semejanza suya (cf. Gen 1,26), en la sexta edad nace el Señor en la carne; más en concreto todavía, como en el sexto día, los creó varón y mujer, así en la sexta edad nacieron Cristo y la Iglesia. Más aun,

«en el sexto día el hombre es puesto al frente de las bestias, los reptiles y las aves del cielo, de igual manera que en la sexta edad Cristo gobierna las almas que le obedecen. Estas vinieron a su Iglesia, unas de los gentiles, otras del pueblo judío, para que Él domeñase y amansase a los hombres,

ya a los entregados a la concupiscencia de la carne -equiparados a las bestias-, ya a los cegados por la tenebrosa curiosidad -equiparados a los reptiles-,

ya a los envanecidos por el orgullo-equiparados a las aves-» 60 .

El santo no se atiene aquí a la terminología específica de san Juan al señalar las tres concupiscencias. La realidad última, sin embargo, es la misma. Lo que interesa es, primero, la afirmación explícita de que las especies de animales sobre las que Dios mandó al hombre que dominase: bestias, reptiles, aves, son símbolo de las personas entregadas a cada una de las concupiscencias: la de la carne, la de la curiosidad y la del orgullo; segundo, que, con la misma claridad, presenta al hombre que ha de dominar sobre tales animales como símbolo de Cristo que «domestica» a tales hombres, esto es, que domina a cada una de las concupiscencias. Con otras palabras: pone fin a la perversión del deseo, pues, al dominar sobre él, lo orienta hacia sí.

3.4.2. El segundo texto corresponde al libro primero de la obra $D e$ doctrina christiana, escrito hacia el 397. En él expone cuáles son las res o contenidos en la Escritura, distinguiendo tres clases: unas que han de ser objeto de disfrute (frui), otras que han de ser objeto de uso (uti) y otras, por fin, que

60. «Et praeponitur homo illo die pecoribus et serpentibus et volatilibus caeli, sicut in ista aetate Christus regit animas obtemperantes sibi, quae ad ecclesiam eius, partim de gentibus, partim de populo iudaeorum venerunt, ut ab eo domarentur atque mansuescerent homines, vel carnali concupiscentiae dediti sicut pecora, vel tenebrosa curiositate oscurati quasi serpentes, vel elati superbia quasi aves» (De genesi adversus manichaeos 1,33,40: PL 35,192-193). 
pueden ser objeto de uso y de disfrute ${ }^{61}$. Luego se detiene en mostrar cuáles son esas realidades objeto del frui, identificándolas con las personas de la Santísima Trinidad, el Padre, el Hijo y el Espíritu Santo ${ }^{62}$. Pero, aunque están a disposición de los hombres, estos no las logran porque «son, por así decir, rechazados de la patria por los vientos contrarios de sus costumbres depravadas. Se van tras los bienes de menor categoría e inferiores a aquellos mismos que personalmente reconocen como mejores y superiores» 63 . De ahí que sea necesaria la purificación ${ }^{64}$, posible gracias a la encarnación de Jesucristo. Escribe el santo:

«Deseando sanar al hombre, la Sabiduría de Dios se presentó personalmente para llevar a cabo dicha obra, conviertiéndose ella misma en médico y en medicamento a la vez. Así, pues,

dado que el hombre cayó por orgullo, ella recurrió a la humildad para curarlo; dado que fuimos engañados por la sabiduría de la serpiente, fuimos liberados por la necedad de Dios...;

nosotros hicimos mal uso de la inmortalidad, razón por la que morimos; Cristo hizo buen uso de la mortalidad, razón por la que vivimos. Por el espíritu corrompido de una mujer entró la enfermedad; del cuerpo virgen de una mujer surgió la salud» 65 .

Al presentar a Cristo, Sabiduría divina, como médico y medicamento, alude indirectamente a la situación de enfermedad en que se hallaban aquellos a los que vino. Para la referencia anterior a tal enfermedad el santo no recurrió al esquema de las tres concupiscencias. Pero el esquema sí aparece, en cambio, en el trasfondo, al describir la obra sanadora. De hecho, es fácil reconocer en el texto citado la referencia tanto a las tres partes de la filosofía . como a las tres concupiscencias. El orgullo (su contrario, la humildad) remite a la filosofía moral y a la ambición mundana; la sabiduría (su contrario, la necedad), a la filosofía racional y a la concupiscencia de los ojos; la corrup-

61. De doctr. christ. I,3,3; CC 32,8. Sólo una perífrasis permitiría traducir con exactitud los términos latinos aquí usados. Cf., al respecto L. VerHeIJEN, Le première livre du De doctrina christiana, p. 171. Todo el artículo es enriquecedor, ayudando a comprender mejor el pensamiento del santo respecto de cada una de esas tres res.

62. Ib. I,5,5: CC 32,9.

63. Ib. I,9,9: CC 32,11-12.

64. Ib. I,10,10: CC 32,12

65. «... sic sapientia Dei hominem curans, se ipsam exhibuit ad sanandum, ipsa medicus, ipsa medicina. Quia ergo per superbiam homo lapsus est, humilitatem adhibuit ad sanandum. Serpentis sapientia decepti sumus, Dei stultitia liberamur... Nos inmortalitate male usi sumus, ut moreremur; Christus mortalitate bene usus est, ut uiueremus. Corrupto animo feminae ingressus est morbus; integro corpore feminae processit salus» $(1,14,13$ : CC 32,14$)$. 
ción (su contrario, la salud), a la filosofía natural y a la concupiscencia de la carne.

Lo que nos interesa, sobre todo, es señalar que san Agustín especifica la obra de Cristo, poniéndola en relación implícita al menos con cada una de las tres concupiscencias. Su encarnación significa la superación de todas ellas.

3.4.3. Hay todavía otros textos en que san Agustín vincula muy estrechamente las tres concupiscencias con la persona de Jesucristo, en cuanto superador de las mismas. Nos referimos a aquellos en que expone las tentaciones a que el diablo sometió a Jesús en el desierto (Mt 4,1-11; Mc 1,12-13; Lc 4,113) ${ }^{66}$.

El exégeta distingue dos clases de tentaciones: una en que el tentador trata de conseguir lo que pretende recurriendo a los atractivos mundanos (blandimenta); otra en que se sirve del temor 67. Utilizando imágenes bíblicas, en la primera presenta al tentador disfrazado de serpiente insidiosa, en la segunda de león rugiente 68 . Por lo que se refiere al Señor, esta segunda la sufrió en la pasión; a ella alude el evangelista san Lucas al decir: Acabada la tentación, el diablo se alejó de él «hasta el tiempo oportuno» (Lc 4,13); la primera en el desierto, donde la sufrió en la triple forma en que puede ser puesta a prueba la apetencia humana: mediante el placer, la curiosidad o la soberbia. Según el santo, la primera tentación de Jesús se corresponde con la concupiscencia o deseo de la carne; la segunda (según san Mateo, tercera según san Lucas) con la concupiscencia de los ojos; la tercera (según san Mateo, segunda según san Lucas) con la ambición mundana. Todo lector del evangelio sabe que Jesús superó las tentaciones y, por tanto, las concupiscencias.

Una vez más, Cristo aparece puesto en relación específica con cada una de las tres concupiscencias en condición de vencedor de las mismas. Pero esta relación específica ha de ser complementada con otro aspecto. San Agustín no se limita a poner de relieve el hecho; más hincapié hace en el porqué se sometió a ellas. En su opinión lo hizo para enseñar al cristiano a luchar, pues

66. Cf. De uera religione 38,71: CC 32,233-234 (a. 390); En. in ps. 8,13: CC 38,55-57 (a. 392 o 394); Sermo 284,5: PL 38,1291-1292; Tractatus in Ioannis epistulam al Parthos 2,13-14: PL 35,1996-1997 (a. 407).

Cf. G. LEONARDI, Le tentazioi di Gesù nella interpretazione patristica, en Studia Pataviana 15 (1968) 229-262; espec. pp. 255-256. Según este estudio, san Agustín es el único autor de la época patrística que con certeza establece una correspondencia entre las tres tentaciones sufridas por Jesús y la triple concupiscencia mencionada por 1 Jn 2,16 (ib. p. 261).

67. Cf. En. in ps 8,13: CC 38,55-57; Sermo 284,5: PL 38,1291-1292; cf. también En. in ps. 30 II,1,10: CC 38,187-189.

68. Sermo 284,5: PL 38,1291-1292. 
las tentaciones a las que tuvo que enfrentarse Jesucristo son las mismas a las que tiene que enfrentarse él. Como maestro, dice, enseñó a sus discípulos con qué armas han de enfrentarse al enemigo: con la palabra de Dios. Pero tampoco se conforma con presentar sólo el ejemplo de Jesús; a sus oyentes ofrece, además, otro recurso para superar la prueba, que parte de una lectura en profundidad de las palabras con que Jesucristo salió victorioso.

Al respecto, merece consideración especial el sermón 284, predicado según algunos autores el año 418, pero, según otros, el 397 69. Con ocasión de hablar de los mártires que combatieron hasta la muerte en pro de la verdad (Sir 4,33), introduce el ejemplo de Cristo en lucha con el diablo en el desierto. Como tantas otras veces, aduce la razón por la que Cristo permitió ser tentado. Hela aquí:

«¿Por qué permitió que le tentara, sino para enseñarnos a ofrecer resistencia al tentador?

Si el mundo te promete el placer carnal, respóndele: "Más deleitoso es Dios".

$\mathrm{Si}$ el mundo te promete honores y dignidades seculares, respóndele: "El reino de Dios es más excelso que todo".

Si el mundo te promete curiosidades superfluas o dañinas, respóndele: “Sólo la verdad de Dios no se equivoca"» 70 .

La novedad del texto está en indicar el mecanismo mediante el cual se puede superar el atractivo de las concupiscencias. Es evidente que erraría el camino quien tratase de suprimir el deseo, arraigado en el mismo ser del hombre. Lo metodológicamente correcto consiste en ofrecerle la posibilidad de satisfacerse en un objeto de superior categoría, en brindarle una alternativa superior. Es lo que propone aquí el santo. El deseo del hombre es reorientado hacia Dios. En él el hombre encontrará en plenitud lo que mendiga de las concupiscencias.

Podemos ya sintetizar. Por su procedencia de Dios, el hombre experimenta un triple deseo, innato, en su mismo ser. El pecado de origen torció su dirección y el deseo legítimo se tornó en triple concupiscencia, dañina y a la larga destructora; en enfermedad, por tanto. Esta enfermedad hizo necesaria

69. Optan por el 418, Morin, Konzelmann y La Bonnardière; por el 397, Lambot y Perler. Cf. P. VERBRAKEN, Études critiques sur les sermons de saint Augustin, Steenbrugis 1976, p. 128.

70. «Quare se permisit tentari, nisi ut doceret resistere tentatori? Promittit mundus carnalem voluptatem, responde illi: Delectabilior est Deus. Promittit mundus honores et sublimitates saeculares, responde illi: Altius est omnibus regunum Dei. Promittit mundus superfluas et damnabiles curiositates, responde illi: Sola non errat veritas Dei» (S. 284,5: PL 38, 1291). 
la presencia del médico, el Hijo de Dios hecho hombre. En su misma persona se mostró vencedor de ese triple mal, mal que sigue venciendo en quienes recurren a su arte. Su terapia: ofrecer algo mejor. ¿Cuál es esa realidad mejor? En el sermón citado, san Agustín hablada del deleite que produce Dios, de la excelsitud del reino de Dios y de inerrancia de la verdad de Dios. En definitiva, Dios. Dios es la alternativa a la triple concupiscencia. Pero en otros textos Agustín concretará más: ese Dios es Jesucristo mismo. Lo que ofrecen las concupiscencias lo otorga Jesucristo mismo de forma más plena y auténtica. Como aparecerán en su momento, no es necesario traerlos aquí.

Si alguien quisiera demostrar que en el desierto arenoso y árido ha nacido una flor, necesitaría pruebas sólidas para convencer; si, por el contrario, pretendiera mostrar que ha nacido en un cuidado jardín le sería mucho más fácil, porque es natural que en un jardín haya flores. Esta imagen tiene por finalidad dar razón de las premisas anteriores. Con ellas no hemos pretendido sino mostrar que nuestra propuesta no nace como rara flor en el desierto, sino como una flor más en un jardín en que abundan. La propuesta, pues, es asumible de entrada. No pedimos al texto algo que su autor no estaba capacitado o dispuesto a dar, sino algo que él regalaba con absoluta generosidad.

(continuará)

Pío DE LUIS, OSA

Estudio Teológico Agustinano

Valladolid 